(HIV), the cause of acquired immune deficiency syndrome (AIDS). Activities highlighted the role communities played in controlling the epidemic of HIV infections and AIDS. On December 1, 1992, WHO, governmental, and nongovernmental organizations throughout the world held special events designed to increase knowledge and understanding about AIDS and to encourage compassion for persons infected with HIV.

In conjunction with the event, the US Public Health Service designated December 1 as National AIDS Awareness Day. Information about HIV infection, AIDS, and World AIDS Day is available from the Centers for Disease Control and Prevention National AIDS Hotline (CDC NAH) and the CDC National AIDS Clearinghouse (CDC NAC). The CDC NAH provides callers with information about HIV/ AIDS, refers callers to services in their community, and places orders for HIV/ AIDS publications; the CDC NAC distributes materials and maintains data bases on AIDS service organizations, educational materials, funding sources, and drug trials. The telephone numbers for the CDC NAH are (800) 342-2437 ([800] 342-AIDS); Spanish, (800) 3447432 ([800] 344-SIDA); or deaf service, (800) 243-7889 ([800] AIDS-STTY). For the CDC NAC, the number is (800) 4585231.

\section{States To Adopt Policies for HIV- Infected Healthcare Workers Performing Exposure-Prone Procedures}

October 28, 1992, marked the deadline for state public health officials to certify to the Secretary of Health and Human Services that guidelines issued by the Centers for Disease Control and Prevention (CDC) for managing human immunodeficiency virus (HIV) and hepatitis B virus (HBV)-infected healthcare workers performing exposure-prone invasive procedures, or equivalent guidelines, have been implemented in each state. The federal law (section 663 of Public Law 102-141) refers to the CDC's July 12, 1991 “Recommendations for preventing transmission of human immunodeficiency virus and hepatitis B virus to patients during exposure-prone invasive procedures" (any current version of the guideline).

Many states have already applied for a one-year extension until after October 1993, some in anticipation of a revision of the CDC recommendations. However, the CDC has recently indicated that the July 12,1991 , recommendations will not be modified. In a letter to the state public health officers, Dr. William Roper announced that their review of the state guide- lines, with respect to their equivalency to the July 12 recommendations, will give appropriate consideration to those states that decide exposure-prone invasive procedures are best determined on a case-by-case basis, taking into consideration the specific procedure as well as the skill, technique, and possible impairment of the infected healthcare worker. The law does not define the term "equivalency." As such, the final decision lies with the CDC.

It is not entirely clear how "equivalency" will be determined; however, experts believe that the CDC may be inclined to allow certain flexibility. In a New York Times article on June 6, 1992, Dr. Roper stated that he would be inclined to approve guidelines developed by New York State, which emphasize voluntary testing of healthcare workers, case-by-case evaluation of infection workers to determine if they pose a significant risk to patients, and confidentiality regarding the infection status of any healthcare worker who is determined to be fit for duty. Additionally, the New York State policy requires periodic infection control training, as well as monitoring and enforcement of universal precautions.

The CDC also recently reported on the continuing investigation of patients who have been treated by healthcare workers infected with HIV. ${ }^{1}$ These ongoing investigations of more than 15,000 patients have disclosed no further evidence of HIV transmission from a healthcare worker to a patient, beyond the previously reported Florida cluster of HIV transmission in a dental practice. ${ }^{2}$ This report from the CDC support the statements in their July 12 recommendations that the risk of HIV transmission from a healthcare worker to a patient is small and that mandatory testing of healthcare workers is not justified.

State health departments will be working with healthcare professional groups, hospital associations, healthcare providers, and others to draft appropriate guidelines, while awaiting any additional changes in interpretation that may arise from the new Clinton administration.

\section{REFERENCES}

1. Centers for Disease Control. Update: investigation of patients who have been treated by HIV-infected health care workers MMWR. 1992;41:344-346.

2. Ciesielski C. Marlancs D, Ou C-Y, et al. Transmission of human immunodeficiency virus in a dental practice. Ann Intern Med. 1992;116:798-805.

Update on Safe Medical Device Act Some hospitals and other "user" facilities, including ambulatory surgical facilities, nursing homes, and outpatient treatment centers, may not be aware that 